\title{
Earth's deep crust could support widespread life
}

Discovery of hydrogen-rich waters hints at unexplored microbial ecosystems.

Hannah Hoag

17 December 2014 | Corrected: 18 December 2014

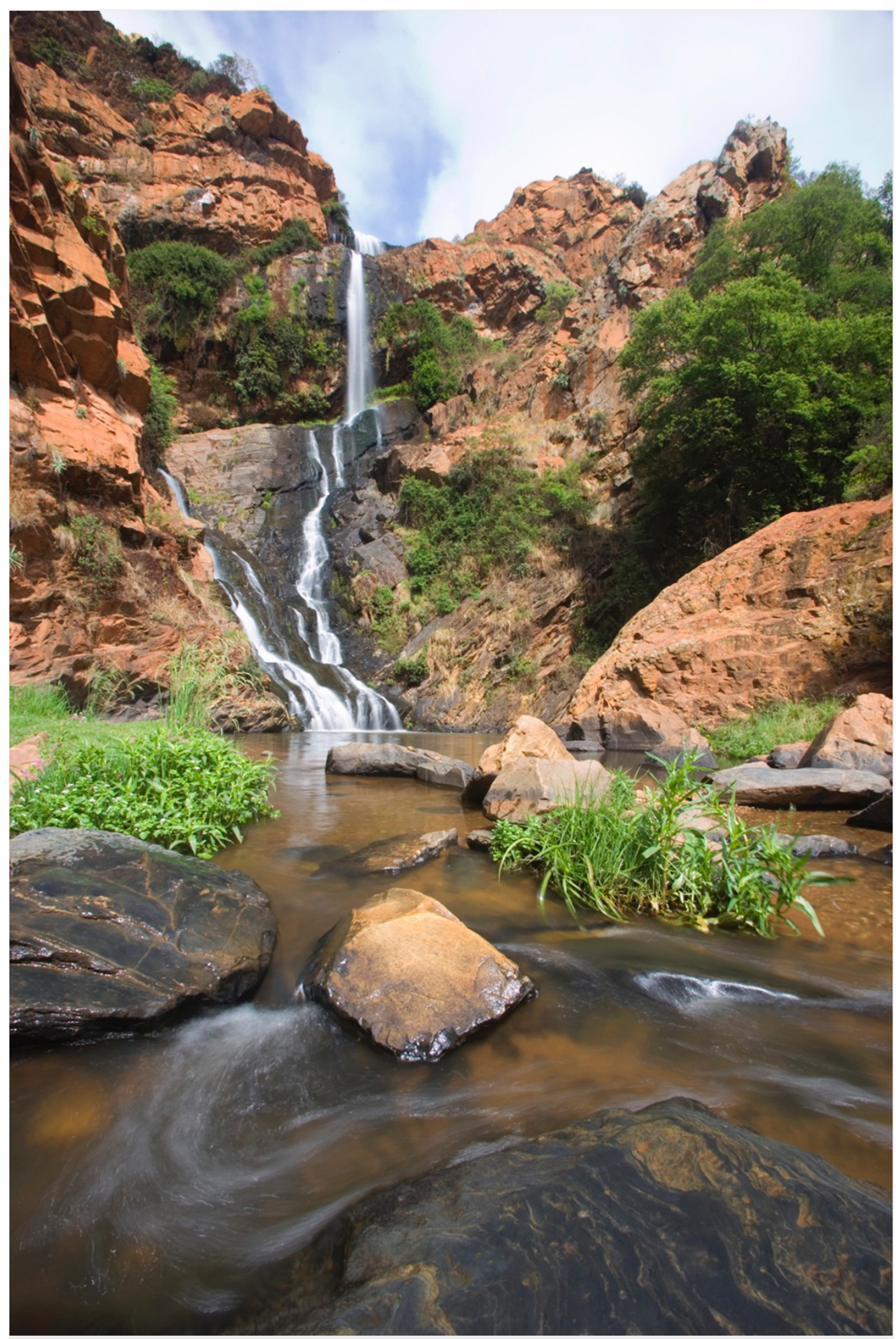

Gallo Images/Superstock

Hydrogen-eating microbes live in rock 4 kilometres below the surface of the Witwatersrand basin in South Africa. 
conditions near hydrothermal vents, which host thriving ecosystems.

The finding, published on 17 December in Nature ${ }^{1}$, provides a road map with which to search for deep microbial life on Earth and possibly Mars.

Scientists once thought that subsurface microbial ecosystems consumed energy that filtered down from Earth's surface, implying that such ecosystems ultimately depended on sunlight and photosynthesis. But the discovery of deep microbial biomes that feed on chemicals such as hydrogen has raised questions about how widespread these communities are.

Searching for an answer, Barbara Sherwood Lollar, a geoscientist at the University of Toronto, Canada, and her colleagues pulled together data on hydrogen production from more than 200 boreholes at 32 mining sites, mostly in Canada, South Africa and Scandinavia. The researchers used this information to estimate how much hydrogen gas is produced deep in the oldest parts of the continental crust, which could help to identify areas that might host subsurface life.

The team calculates that the oldest rock on Earth — the 550-million- to 4.6-billion-year-old Precambrian continental lithosphere produces roughly 100 times more gas annually than scientists previously thought. Two chemical reactions produce the gas, including one in which natural radioactivity within the rock splits water molecules into hydrogen and oxygen.

The new estimate effectively doubles the energy available from hydrogen gas dissolved in water in the rock and at deep-sea hydrothermal vents.

"This massively changes the concept of where life can be on this planet," says Sherwood Lollar, because more than $70 \%$ of the rock that forms the continents dates to Precambrian times.

\section{Early life}

In 2006, scientists discovered hydrogen-eating, rock-dwelling microbes living 4 kilometres below the surface of the Witwatersrand basin in South Africa ${ }^{2}$. But Sherwood Lollar's team shows that other sites, including those in Finland and Canada — where she and her colleagues recently identified ancient water more than one billion years old ${ }^{3}$ — show higher hydrogen-gas levels, suggesting that they may be more hospitable to microbial life.

"That's fascinating," says Sean McMahon, a geomicrobiologist at Yale University in New Haven, Connecticut. "The microbiology hasn't been done for most of the other boreholes — and it probably should."

The finding could help scientists to better understand early life on Earth. One debate centres on how life might have spread and diversified after forming at marine hydrothermal vents, says Emily Catherine Pope, a geochemist at the Natural History Museum of Denmark in Copenhagen.

"If you identify a source of energy that's everywhere, it's no longer a limiting factor for the spread of life," she adds.

The new finding could also lead scientists to study areas of Earth that resemble Martian geology by drilling boreholes in cratons, the thick, ancient central cores of the continents. "You can get a lot deeper before you reach the maximum temperature for life — that's where you'd expect to find the deepest living things," says McMahon.

Nature I doi:10.1038/nature.2014.16575

\section{Corrections}

Corrected:This story accidentally misquoted Sean McMahon as saying that microbiology hasn't been done on the Finnish boreholes — it has. His quote has now been corrected.

\section{References}

1. Sherwood Lollar, B., Onstott, T. C., Lacrampe-Couloume, G. \& Ballentine, C. J. Nature 516, 379-382 (2014).

2. Lin, L.-H. et al. Science 314, 479-482 (2006). 
3. Holland, G. et al. Nature 497, 357-360 (2013). 